Eur. J. Clin. Chem. Clin. Biochem.

Vol. 31,1993 , pp. $221-224$

(C) 1993 Walter de Gruyter \& Co. Berlin - New York

\title{
Neopterin in Patients with Choroidal Melanoma
}

\author{
By H. Gerding, G. Cremer-Bartels, K. Krause and H. Busse \\ Dept. of Ophthalmology, University of Münster, Germany
}

(Received September 18, 1992)*

Summary: Neopterin excretion in urine and the serum concentrations of neopterin were compared in 101 patients with a malignant melanoma of the choroid and in a matched group of healthy volunteers. The majority of cases $(n=99)$ presented an untreated $(n=20)$ or treated and either partially $(n=33)$ or completely regressed $(n=47)$ melanoma of stage I-III without signs of extraocular manifestation at the time of analyses. The incidence of elevated neopterin concentrations in all melanoma patients beyond the upper limit $(\vec{x}+2$ S.D. of healthy controls) was $16 \%$ for both serum and urine. In patients with critical events, for example orbital infiltration or delayed metastatic disease during the subsequent follow-up period (at least 14 months), the neopterin concentrations were at the higher end of distribution. One patient with verified metastatic disease at the time of analysis presented extremely elevated neopterin concentrations in serum $(82.3 \mathrm{nmol} / \mathrm{l})$ and urine $(1608 \mu \mathrm{mol} / \mathrm{mol}$ creatinine $)$. It seems that the results of neopterin analyses are informative as a prognostic factor for the follow-up of patients with a malignant melanoma of the choroid.

\section{Introduction}

In recent years neopterin has been established as a clinically useful indicator of cellular immunity and, therefore, of tumour-associated cellular reactions $(1-4)$. Neopterin-positive cases are regularly associated with haematological neoplasias, whereas in most kinds of solid tumours the association of a neopterin increase tends to be less frequent. In certain types of solid tumours neopterin correlates with staging $(2,5)$ and seems to be useful as a prognostic factor for the monitoring of affected patients, whereas in most other situations neopterin concentrations are independent of the tumour stage. Patients with malignant melanoma of the choroid have so far not been the focus of neopterin analyses, but there is one report of elevated neopterin levels in cases of cutaneous malignant melanomas with visceral metastases (5). Since both kinds of tumour share some immunological properties (6), and the longterm prognosis of choroidal mela-

\footnotetext{
* Submitted February 7/August 31, 1992 to "Pteridines" which discontinued with vol. 3 , no. 3,1992
}

noma is much better than that of cutaneous melanoma, it seemed worthwhile to look for a relation between neopterin and tumour stage, as well as possible correlation with the occurence of metastases.

\section{Material and Methods}

One hundred and one patients with a malignant melanoma of the choroid were enroled in this study on neopterin excretion. According to the clinical situation patients were classified as:

(a) untreated,

(b) incomplete tumour regression after brachytherapy with ${ }^{106} \mathrm{Ru} /{ }^{106} \mathrm{Rh}$-applicators,

(c) presumed complete tumour regression after brachytherapy.

In addition, neopterin was determined in the sera of 43 of these patients. At the time of pterin analysis one patient presented metastases of the tumour (hepatic, pulmonary, osseous; stage IVb). In two further patients metastases were diagnosed during the period of clinical follow up (at least 14 months), 7 and 10 months after analysis, respectively. One patient presented a transscleral infiltration of the orbita (stage IVa). Neopterin results from tumour patients were compared with those from healthy volunteers. Healthy controls for this study were selected so that they matched the patients as closely as possible with respect to sex and age. For basic statistical information on the age and sex-ratio of examined groups see table 1. 
Tab. 1. Statistical characterisation of the examined groups of patients with choroidal melanoma and healthy controls ( $\mathrm{F}=$ female, $\mathrm{M}=$ male, $\mathrm{n}=$ number of patients).

\begin{tabular}{|c|c|c|c|c|}
\hline & \multicolumn{2}{|l|}{ Urine } & \multicolumn{2}{|l|}{ Serum } \\
\hline & Melanoma & Control & Melanoma & Control \\
\hline (n) & 101 & 92 & 43 & 40 \\
\hline$\underset{\text { (years) }}{\text { Age } \bar{x} \pm S . D .}$ & $\begin{array}{r}61.3 \\
\pm 11.9\end{array}$ & $\begin{array}{r}59.2 \\
\pm 12.5\end{array}$ & $\begin{array}{r}60.5 \\
\pm 10.8\end{array}$ & $\begin{array}{r}59.8 \\
\pm 11.4\end{array}$ \\
\hline $\begin{array}{l}\text { Age (range) } \\
\text { (years) }\end{array}$ & $\begin{array}{r}48 \\
-88\end{array}$ & $\begin{array}{r}47 \\
-84\end{array}$ & $\begin{array}{r}48 \\
-88\end{array}$ & $\begin{array}{r}47 \\
-83\end{array}$ \\
\hline $\operatorname{Sex} q: \hat{\jmath}$ & $54: 47$ & $48: 44$ & $23: 20$ & $21: 19$ \\
\hline
\end{tabular}

Samples were collected from all patients and healthy volunteers between 9 and 12 o'clock in the morning, in order to avoid any bias by circadian variations (7).

Neopterin analysis of urine and serum was performed under oxidative conditions by fluorometric HPLC-detection. Urine was analysed according to Goldberg's (8) modification of the Fukushima \& Nixon (9) procedure. Immediately after collection, $1 \mathrm{ml}$ of each specimen was incubated with $300 \mu \mathrm{l}$ of $1 \mathrm{~mol} / 1$ $\mathrm{HCl}$ and $200 \mu \mathrm{l}$ of $5 \mathrm{~g} / 1 \mathrm{I}_{2} / 10 \mathrm{~g} / \mathrm{l} \mathrm{KI}$ in $0.1 \mathrm{~mol} / \mathrm{l} \mathrm{HCl}$ in darkness. After $1 \mathrm{~h}$, excess iodine was reduced with $200 \mu \mathrm{l}$ of ascorbic acid. Further purification was performed with Dowex $\mathrm{H}^{+}$ (Dowex $50 \mathrm{WX8}, 100-200$ mesh) as previously reported (8). Serum samples $(3 \mathrm{ml})$ were incubated with $2 \mathrm{ml}$ of $2 \mathrm{~mol} / \mathrm{l}$ trichloroacetic acid. Iodine was added to this incubation in the same proportion as in the oxidative step of the urine analyses. After reduction of exess iodine with ascorbic acid the mixture was centrifuged. The supernatant was further purified by Dowex $\mathrm{H}^{+}$chromatography (9) and subsequently filtered (Amicon YM 10, $4000 \mathrm{~g}, 30 \mathrm{~min},+4^{\circ} \mathrm{C}$ ). The HPLC-procedure was performed as described by Goldberg et al. (8). The ratio of neopterin determined after oxidation to native neopterin determined by non-oxidative analysis is $1: 0.46$ (urine) and $1: 0.42$ (serum).

Creatinine concentrations in urine were determined with the kit (No. 124192) of Boehringer (Mannheim, Germany). All pterins were from Dr. B. Schircks (Jona, Switzerland).

\section{Results}

The results of urine analyses of all melanoma patients compared with the normal range (mean \pm 2 standard deviations) are shown in fig. 1 . The majority of patients (85 of 101) presented urinary neopterin concentrations below the upper normal limit (mean +2 S. D. of healthy controls). Urinary neopterin excretion of the only patient in this study with verified metastatic disease ( ${ }^{*} \mathrm{M}$ in fig. 1$)$ at the time of analyses was greatly elevated $(1608 \mu \mathrm{mol} / \mathrm{mol}$ creatinine). Results for the two patients with a latency of diagnosed metastases ( $m$ in fig. 1) and for one patient with orbital infiltration (s) rank near the upper normal limit. Neopterin was elevated in the serum of 7 of 43 melanoma patients $(16 \%)$. The result for the abovementioned patient with metastatic disease at the time of analysis was distinctly $(1 \rightarrow$ in fig. 2$)$ elevated by a

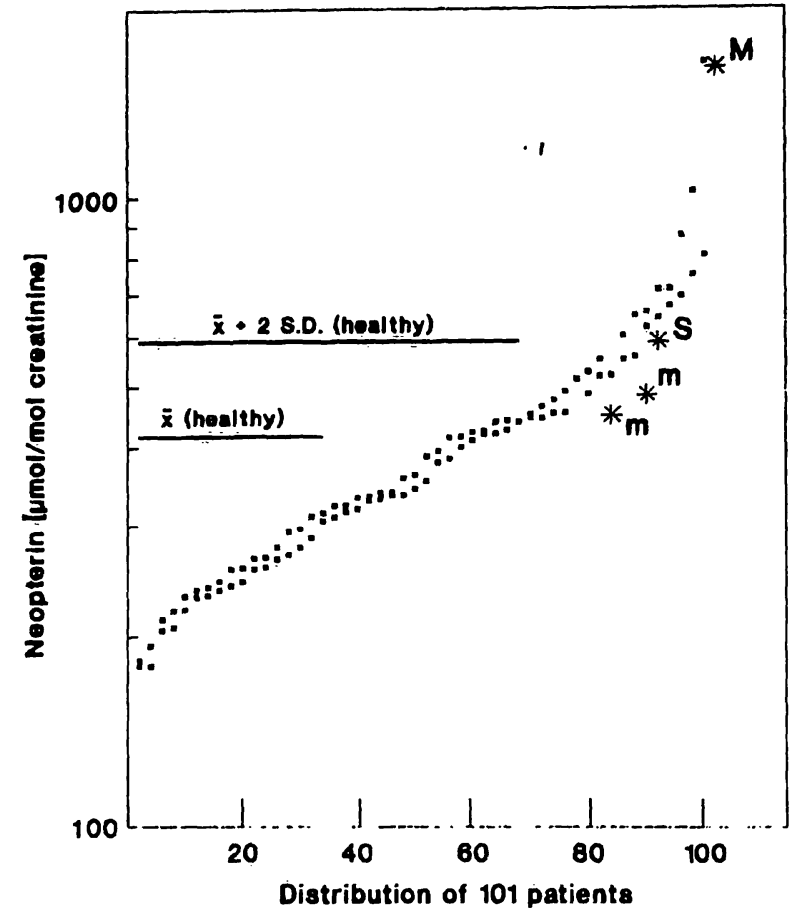

Fig. 1. Neopterin excretion by 101 patients with a choroidal melanoma. $M=$ Patient with verified metastatic disease at the time of analyses, $m=$ results of patients with later diagnoses of metastases ( 7 and 10 months later), $\mathrm{S}=$ melanoma patient with transscleral infiltration of the orbit. Results of patients with an index $(M, m, S)$ are represented by an asterisk (*). Differences between tumour patients and healthy controls were not significant according to the result of Student's t-test ( $p>0.8)$.

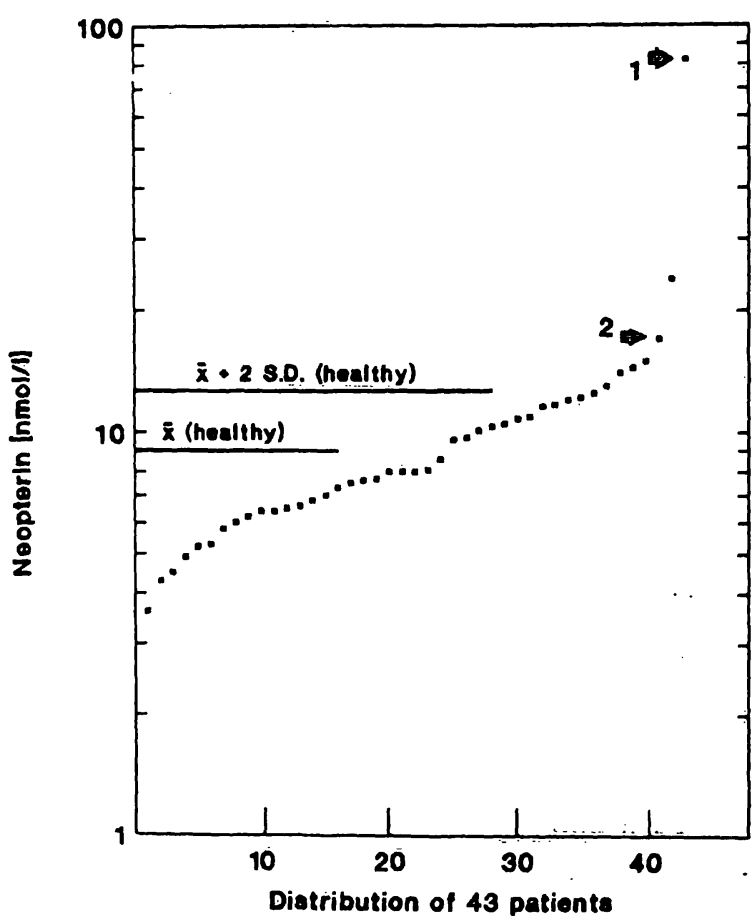

Fig. 2. Neopterin in serum of 43 patients with a choroidal melanoma, in relation to the range of healthy normals. " $1 \rightarrow$ " indicates the result of an untreated melanoma patient with metastatic disease, " $2 \rightarrow$ " of an untreated melanoma patient with diagnosed metastatic disease 7 months after neopterin analyses. Differences between normals and tumour patients were not significant (Student's t-test, $\mathrm{p}>0.9$ ). 
Tab. 2. Neopterin in urine and serum of patients with choroidal melanoma compared with results of a healthy control group.

\begin{tabular}{|c|c|c|}
\hline & $\begin{array}{l}\text { Urine } \\
\text { ( } \mu \mathrm{mol} / \mathrm{mol} \\
\text { creatinine) }\end{array}$ & $\begin{array}{l}\text { Serum } \\
\text { (nmol/l) }\end{array}$ \\
\hline $\begin{array}{l}\text { Untreated,tumour patients } \\
\text { (n) }\end{array}$ & $\begin{array}{l}375 \pm 172 \\
(17)\end{array}$ & $\begin{array}{l}8.7 \pm 1.5 \\
(8)\end{array}$ \\
\hline $\begin{array}{l}\text { Partial tumour regression } \\
\text { (n) }\end{array}$ & $\begin{array}{l}423 \pm 256 \\
(33)\end{array}$ & $\underset{(19)}{8.7} \pm 3.5$ \\
\hline $\begin{array}{l}\text { Complete tumour regression } \\
\text { (n) }\end{array}$ & $\begin{array}{l}394 \pm 179 \\
(47)\end{array}$ & $\begin{array}{l}9.7 \pm 3.0 \\
(14)\end{array}$ \\
\hline $\begin{array}{l}\text { Healthy controls } \\
\text { (n) }\end{array}$ & $\begin{array}{l}410 \pm 101 \\
(92)\end{array}$ & $\underset{(40)}{9.1} \pm 1.6$ \\
\hline
\end{tabular}

Patients with present or later metastatic disease and orbital infiltration (" $M$ ", " $m$ ", " $S$ " and " $\rightarrow$ " of figure 1 and 2) are not included in this table ( $n=4$ for urine, $n=2$ for serum). The absolute number and percentages of melanoma patients exceeding the upper limit of healthy controls (mean $\pm 2 \mathrm{~S}$. D.) are listed in table 3.

factor of 9 , compared with the mean of the control group. The second array $(2 \rightarrow$ in fig. 2$)$ indicates the results for a patient diagnosed as having metastases (liver) 7 months after pterin analyses.

The results of neopterin measurements in urine and serum grouped according to the actual tumour state are shown in table 2 . Significant differences were not found in the ANOVA (F-test) at a level of $p<0.1$. The relative incidence of patients exceeding the upper limit $(\bar{x}+2$ S. D.) was rather consistent in all classified groups of patients, as seen in table 3 .

\section{Discussion}

In summary, neopterin excretion in urine and the serum concentrations of neopterin in patients with malignant choroidal melanoma was elevated beyond the upper limit only in a minor percentage $(16 \%)$ of all examined subjects. This result resembles the reported magnitude of significantly increased neopterin levels in other types of solid malignant tumours, for example, early stage (I-III) breast cancer (10), and head and neck cancer $(11,12)$. The relative incidence of neopterin elevation beyond the upper limit infers that neopterin concentrations are unsuitable as a tool
Tab. 3. Relative incidence of neopterin results of patients with choroidal melanoma exceeding the upper limit of bealthy normals (mean +2 S. D.).

\begin{tabular}{lrlllll}
\hline & \multicolumn{2}{c}{ Urine } & & & \multicolumn{2}{l}{ Serum } \\
\cline { 2 - 3 } \cline { 7 - 8 } \cline { 7 - 8 } & $\mathrm{n}$ & & & $\mathrm{n}$ & $\%$ \\
\hline Untreated tumour patients & $4 / 20$ & 20 & & $2 / 10$ & 20.0 \\
Partial tumour regression & $5 / 34$ & 15 & & $3 / 19$ & 16 \\
Complete tumour regression & $7 / 47$ & 15 & & $2 / 14$ & 14 \\
All patients & $16 / 101$ & 16 & & $7 / 43$ & 16 \\
\hline
\end{tabular}

for the differentiation of choroidal melanomas from non-neoplastic or other malignant tumours with nearly identical clinical appearance.

The low percentage of indicative neopterin concentrations in patients with choroidal melanoma may have two explanations, related to the possible immunological reactivity of the tumour. First, the average size of choroidal melanomas at the time of diagnosis is small compared with many other malignant tumours, since patients notice subjective symptoms at an early stage of the disease. This may explain why immunological reactions are below a level detectable by neopterin measurement. Second, the tumour-associated immunological reaction of choroidal melanomas is not yet well established, and the available data indicates subnormal immunreactivity, at least in a subgroup of melanoma patients $(13,14)$.

Although the small number of critical events in this series of observation limits the possibility of a prognostic calculation of neopterin results in these patients, it seems that neopterin is informative with respect to metastatic spread of choroidal melanomas. On the basis of the presented results, serum analysis tends to be more discriminative than urine analysis. The observation of elevated neopterin concentration in the serum of a patient with a delayed diagnosis of metastatic spread seems to indicate that neopterin is at least a modest prognostic factor for the follow up of these patients. This will be analysed further.

\section{Acknowledgement}

This work was financially supported by the "Fördergesellschaft der Westfälischen-Wilhelms Universität Münster". Apparative equipment was partially financed by the "Deutsche Forschungsgemeinschaft", project No. Cr 40/11-2.

\section{References}

1. Hausen, A., Fuchs, D., Reibnegger, G., Werner, E. R. \& Wachter, H. (1989) Neopterin in clinical use. Pteridines $l$, 3-10.
2. Reibnegger, G., Bichler, A., Fuchs, D., Hausen, A., Werner, E. R. \& Wachter, H. (1986) in: Tumormarker. Aktuelle Aspekte und klinische Relevanz (Wüst, G., ed.) pp. 284288, Steinkopf, Darmstadt. 
3. Wachter, H., Fuchs, D., Hausen, A., Reibnegger, G. \& Werner, E. R. (1989) Neopterin as marker for activation of cellular immunity: Immunologic basis and clinical application. Adv. Clin. Chem. 27, 81-141.

4. Ziegler, I. (1987) in: Lymphokines, Vol. 14 (Pick, E., ed.) p. 188, Academic Press, New York.

5. Mura, P., Barriere, M., Papet, Y., Reiss, D., Camenen, I., Vaillant, L. \& Lorette, G. (1989) The clinical significance of urinary neopterin in the follow-up of patients after excision of malignant melanoma. Pteridines 1, 19-22.

6. Folberg, R., Donoso, L. A., Atkinson, B., Ernst, C., Herlyn, M. \& Arbizo, V. V. (1985) An antimelanoma monoclonal antibody and the histopathology of uveal melanomas. Arch. Ophthalmol. 103, 275-279.

7. Wever, R. A., Cremer-Bartels, G., Krause, K. \& Gerding, H. (1991) Circadian variations of pterin excretion in humans. In: Pterins and Biogenic Amines in Neurology, Pediatrics, and Immunology (Blau, N., Curtius, H. C. \& Levine, R. A., eds.) pp. 119-134, Lakeshore Publ., Grosse Pointe.

8. Goldberg, M., Gassner, F. \& Merkenschläger, M. (1989) Studies and comparison of urinary pteridine patterns in dogs and cats and their alteration in various neoplasias and virus infections. Pteridines 1, 29-35.
9. Fukushima, T. \& Nixon, J. C. (1980) Analysis of reduced forms of biopterin in biological tissues and fluids. Anal. Biochem. 102, 176-188.

10. Wiegele, J., Margreiter, R., Huber, C., Dworzak, E., Fuchs, D., Hausen, A., Reibnegger, G. \& Wachter, H. (1984) in: Biochemical and Clinical Aspects of Pteridines, Vol. 3 (Pfleiderer, W., Wachter, H. \& Curtius, H. C., eds.) pp. 417424, Walter de Gruyter, Berlin, New York.

11. Dhondt, J. L., Hayte, J. M., Bonneterre, J., Adenis, L., Demaille, A., Ardouin, P. \& Farriaux, J. P. (1982) in: Biochemical and Clinical Aspects of Pteridines. Vol. 1 (Wachter, H., Curtius, H. C., Pfleiderer, W., eds.) pp. 133140, Walter de Gruyter, Berlin, New York.

12. Reibnegger, G., Fuchs, D., Hausen, A., Wachter, H., Bichler, E. \& Böheim, K. (1982) in: Biochemical and Clinical Aspects of Pteridines. Vol. 1 (Wachter, H., Curtius, H. C., Pfleiderer, W., eds.) pp. 207-215, Walter de Gruyter, Berlin, New York.

13. Flynn, K., Feldberg, N. T., Koegel, A., Hager, R., Shields, J. A., Augsburger, J. J. \& Donoso, L. A. (1986) Lymphocyte subpopulation before therapy in patients with uveal malignant melanoma. Am. J. Ophthalmol. 101, 160-163.

14. Dieckhues, B. \& Schmitz, G. (1986) T4- und T8-Lymphozytenbestimmungen beim malignen Melanom der Aderhaut und ihre Bedeutung für die Diagnostik. Fortschr. Ophthalmol. $83,480-482$.

Priv.-Doz. Dr. H. Gerding

Augenklinik der Universität Münster

Domagkstraße 15

W-4400 Münster

Bundesrepublik Deutschland 